\title{
Pregnant versus non-pregnant healthy subjects - a prospective longitudinal musculoskeletal ultrasound study concerning the spectrum of normality
}

\author{
Mihaela Cosmina Micu', Daniela Fodor², Romeo Micu ${ }^{3}$, Sorana Daniela Bolboacă \\ Ruxandra Ionescu ${ }^{5}$
}

${ }^{1}$ Rheumatology Division, $2{ }^{\text {nd }}$ Rehabilitation Department, Rehabilitation Clinical Hospital Cluj- Napoca, ${ }^{2}{ }^{\text {nd }}$ Internal Medicine Department, "Iuliu Hațieganu” University of Medicine and Pharmacy Cluj-Napoca, ${ }^{3}$ Department of Human Assisted Reproduction, ${ }^{\text {st }}$ Gynecology Clinic, University of Medicine and Pharmacy "Iuliu Hatieganu” Cluj- Napoca, ${ }^{4}$ Department of Medical Informatics and Biostatistics, "Iuliu Haţieganu” University of Medicine and Pharmacy ClujNapoca, ${ }^{5}$ Department of Internal Medicine and Rheumatology "Sf. Maria” Hospital, "Carol Davila” University of Medicine and Pharmacy, Bucharest, Romania

\begin{abstract}
Pregnancy induces profound changes in the maternal body and the normality spectrum may differ compared to non-pregnant subjects. Aims: The main objective was to establish the presence, frequency and distribution of articular and peri-articular abnormal findings in healthy women, pregnant and non-pregnant, using clinical examination (CE) and musculoskeletal ultrasound (MSUS). Second objective was to identify which joint/tendon set would show fewer modifications in both groups of healthy subjects and would remain stable throughout pregnancy. Material and methods: A prospective cross-sectional and longitudinal study on healthy pregnant (case group, 5 evaluations $-1^{\text {st }}, 2^{\text {nd }}$, and $3^{\text {rd }}$ trimester of pregnancy and 2 postpartum visits) and non-pregnant female volunteers (control group, one evaluation), consisting in CE vs MSUS joint and tendon evaluation, was conducted. MSUS elementary lesions such as synovial hypertrophy, effusion, Power Doppler (PD) signal, erosions and osteophytes were quantified. Results: The case group (20 pregnant women) and 75 age- matched controls were evaluated on 46 joints and 24 tendon units. The highest frequency of grey scale pathologic-like imaging abnormalities was detected at metatarsophalangeal joints and wrist level in both groups. No pathologic-like abnormalities throughout pregnancy and postpartum were detected on flexor tendons (F1-F5), metacarpophalangeal joints (MCPj), extensor carpi ulnaris tendon (EUC) and large joints (glenohumeral, elbow, tibiotalar). Very low frequency of PD signal, erosions and osteophytes was identified in both groups. The highest longitudinal change was detected in the effusion on joint and tendon level only. Conclusion: MSUS inflammation-like abnormalities can be detected in healthy subjects and pregnancy may modify baseline findings. The identification of a joint/tendon set with less abnormalities (hand flexor tendons F1-F5, MCPj 2-5 and EUC) in healthy subjects would help in selecting target structures, important for identifying the disease onset and for further monitoring.
\end{abstract}

Keyword: joints; tendons; pregnancy; musculoskeletal ultrasound

\section{Introduction}

The definition of "normality" when speaking about peripheral joints and tendons is still a matter of debate

Received 20.04.2018 Accepted 15.06.2018

Med Ultrason

2018, Vol. 20, No 3, 319-327

Corresponding author: Micu Romeo

Assisted Reproduction Department,

Gynecology I Clinic

3-5 Clinicilor street, Cluj- Napoca, Romania

Email: romeomicu@hotmail.com and a problem of perspective. Normal joints and tendons may be defined as the absence of any symptom or clinically detectable sign of pathology on inspection and palpation. Active and passive movements of the anatomical segment/structure and the range of motion must fit within normal ranges, according to statistics performed on large healthy human cohorts [1].

The use of high resolution imaging techniques, suitable for joint and tendon evaluation - musculoskeletal ultrasound (MSUS) and magnetic resonance imaging (MRI) - may face a different reality. Although elementa- 
ry lesions can be accurately detected, normality might be defined in different ways. MSUS is a very useful tool in overcoming the limitations of clinical examination (CE) in different healthy subject/patient categories. The possibility to perform unlimited multi-plane, dynamic and multi-target examinations qualifies MSUS as the favorite imaging tool in the rheumatology clinical practice [2].

Published data constantly confirm that MSUS and MRI are more sensitive than CE and radiography in detecting synovitis, tenosynovitis and erosions in chronic inflammatory rheumatic diseases [3-10]. In addition, MSUS shows a better sensitivity to change $v s \mathrm{CE}$, thus increasing its utility in monitoring the treated patients with rheumatoid arthritis (RA) [11-18].

Several recent studies highlighted the fact that healthy subjects do not have "zero" imaging abnormalities. Joint synovial hypertrophy, positive Doppler signal, effusion, osteophytes and erosions may exist or co-exist in the same healthy subject [19-26]. In addition, tendon involvement in healthy population may represent a very interesting target since $\mathrm{CE}$ shows to be very challenging, especially in complex anatomical areas like the hands and the feet. Currently, scarce and contradictory information are deriving from studies focusing on tendon abnormalities in healthy subjects, most of them used MRI as examination tool [27-29].

Detection by imaging techniques of pathologic-like findings in asymptomatic subjects raised the question if further investigation is needed in order to differentiate a silent pathology from the normality spectrum. This question received no answer by now because longitudinal studies are missing.

Pregnancy induces profound changes in the maternal body, manifested on different stages of evolution and musculoskeletal complaints are quite common in healthy pregnant population. In some cases, chronic rheumatic diseases onset might be experienced during pregnancy [30]. Pregnancy has an important impact on RA, being the only physiologic situation in which affected women may experience clinical improvement and even remission, followed by postpartum deterioration. Still, in some cases, women of childbearing years diagnosed with rheumatic diseases need drug treatment during pregnancy to control the disease activity and to ensure a successful pregnancy outcome [30-33]. In this scenario, the assessment of the disease activity in pregnant patients must rely on a good knowledge of the normal joint and the periarticular changes in healthy pregnant women.

Therefore, the main objective of our study was to establish the presence, frequency and distribution of articular and peri-articular abnormal findings in healthy women, pregnant and non-pregnant, using $\mathrm{CE}$ and
MSUS. Second objective was to identify which joint/tendon set would show fewer modifications in both groups of healthy subjects. Furthermore, this would allow us to choose those joints and tendons more suitable for identifying the disease onset during pregnancy and the followup therapeutic decisions in pregnant patients.

\section{Material and method}

In this prospective cross-sectional and longitudinal study, healthy pregnant (case group) and non-pregnant female volunteers (control group; medical staff and relatives) were recruited between April 2016 - May 2018 for clinical articular/peri-articular and MSUS evaluation. Written informed consent was obtained from all participants. Local Etic Committee approval for the study was obtained.

Inclusion criteria were asymptomatic Caucasian women in reproductive age (18-45 years), non-pregnant and pregnant with normal joint and peri-articular clinical examination at first visit, with no personal history of inflammatory/degenerative joint or peri-articular diseases, with no positive family history for inflammatory and autoimmune rheumatic diseases. In addition, only women with low to moderate physical effort (work, sport) were included. Subjects with known personal history of any acute or sub-acute inflammatory event (including rheumatological pathology), history of any chronic inflammatory rheumatic, autoimmune or degenerative joint disease, personal history of joint/peri-articular trauma in the last 2 years, administration of pain killers, or corticosteroids (CS) in the last 6 weeks and high physical effort were excluded.

Demographic, clinical and MSUS data collection was made for both groups. CE was performed on the same day by 2 different experienced rheumatologists. MSUS evaluation was made by a senior doctor with $>10$ years of experience. Duration of the CE was of 20 minutes $v s$ 1 hour and 15 minutes for MSUS, including paperwork.

Non-pregnant women were examined one time. Pregnant healthy subjects were recruited in the $1^{\text {st }}$ trimester of pregnancy. They underwent 4 more follow up examinations scheduled in the $2^{\text {nd }}, 3^{\text {rd }}$ trimester and 2 postpartum examinations at 3-6 months and 12 months after delivery, totalizing 5 visits. Only data obtained from subjects attending to all requested visits were analyzed.

\section{Clinical examination}

$\mathrm{CE}$ was focused on the following anatomic regions and structures: hands (wrist, metacarpophalangeal joints [MCPj] 1-5, proximal interphalangeal joints [PIPj] 1-5, bilateral hand extensor tendon compartments $1-6$, flexor pollicis longus tendon and superficial and profound flex- 
ors of the digits 2-5 [F1-F5]), feet (metatarsophalangeal joints [MTPj] 1-5), gleno-humeral (GHj) joint, elbow, hip and knee joints, ankle regions bilateral (tibio-talar [TTj], talonavicular [TNj], subtalar joints [STj], tibialis posterior tendon $[\mathrm{TPT}])$. The absence of any pain in active/passive motion along with a normal range of motion qualified the subject for the study. For the case group, after the first examination, occurrence of joint and peri-articular clinical symptoms and signs were recorded along with the number and location.

\section{Ultrasonographic examination}

MSUS evaluation was performed in the same day with the $\mathrm{CE}$, according to current guidelines [2], in the same regions: wrist (radiocarpal and midcarpal joints), MCPj 1-5 dorsal and volar aspect and PIPj 2-5, dorsal and volar aspect, wrist extensor tendon compartments 1-6 (C1-C6), F1-F5, MTPj 1-5 joints dorsal aspect, GHjposterior recess, coronoid, radial and olecranon fossae of the elbow, hip joints- anterior recess, knee joint- recesses, suprapatellar bursa and popliteal space, $\mathrm{TT} \mathrm{j}, \mathrm{TNj}$, $\mathrm{STj}$ (medial, lateral and posterior scan for the last three joints) and TPT. Each flexor tendon of the digit and each extensor tendon compartment of the wrist were considered as single units. If present, following elementary lesions were recorded - joint synovial hypertrophy (SH) in grey scale (GS), intra-articular power Doppler (PD) signal, joint effusion (E), erosions, osteophytes, inflammatory tendon pathology such as SH and E and intrasheath and or intratendon PD signal. The OMERACT definitions for synovitis, tenosynovitis, effusion, erosion and osteophytes were used [34]. Joint and tendon pathology was quantified with semiquantitative scoring systems suitable for small [35] large joints [18] and tendons [36]. For erosions and osteophytes, a dichotomus scoring system was used. Dorsal and volar scoring of $\mathrm{MCPj}$ and PIPj merged into a single joint evaluation. The most important grading for $\mathrm{SH}, \mathrm{E}$ and $\mathrm{PD}$ was chosen to be recorded for a single elementary lesion. Tendon examination was performed in a multi-plane (at the extensor retinaculum for $\mathrm{C} 1-\mathrm{C} 6$ level to the distal insertion, from the flexor retinaculum level up to the distal insertion for F1-F5 and from the retinaculum level up to the insertion on the navicular bone for TPT) and dynamic fashion, according to specific maneuvers.
Erosions were searched at the lateral sites of MCPj 2 and 5 and MTPj 1 and 5. Osteophytes were searched at the level of MCPj, PIPj and MTPj.

MSUS was performed using a GE Logic S8 machine equipped with a 9-15 $\mathrm{MHz}$ broadband multi-frequency matrix linear transducer. GS settings were adjusted in a standardized manner for different anatomic regions. Doppler mode was used in all situations with the following settings: frequency to $7 \mathrm{MHz}$, low wall filter, pulse repetition frequency for small vessels with slow flow $750 \mathrm{~Hz}$. The Doppler gain was adjusted to a level just below the disappearance of background noise. The Doppler box was placed overall joint space, reaching the surface of the skin. Vessel compression was avoided by using an excessive amount of gel between the skin and the transducer.

\section{Statistical analysis}

Quantitative data were tested for normality with Shapiro-Wilk test; the normal distributed data were reported as mean and standard deviation, otherwise the median and IQR (the $1^{\text {st }}$ and $3^{\text {rd }}$ quartiles) were reported. Qualitative data were reported as number of cases and percentages accompanied for large sample size by the associated $95 \%$ confidence intervals calculated with an exact method (similar to the one reported in [37]). Student t-test for independent samples was used to compare normally distributed quantitative data among case and control group; otherwise the Mann Whitney test was applied. Chi-square test or Fisher exact test was used to test the association in the contingency tables. Comparison of frequencies on categorical data in the same group was made with one-sample $Z$ test for proportion. Statistical analysis was done with Statistica program 8.0 (StatSoft Inc, USA) and a p-value $<0.05$ was considered statistically significant.

\section{Results}

Out of 29 pregnant healthy women, 20 completed all 5 visits and formed the case group (age range 27 to 41 years). The control group was represented by 75 healthy, non-pregnant women (age range 19 to 48 years). No significant differences between groups were identified in regard of demographic data (Table I).

Table I. Demographic characteristics of the groups

\begin{tabular}{llll}
\hline Characteristic & Case group $(\mathbf{n = 2 0})$ & Control group $(\mathbf{n}=\mathbf{7 5})$ & p-value \\
\hline Age, years $*$ & $33.50 \pm 3.75$ & $31.88 \pm 8.11$ & 0.201 \\
Physical work $* *$ & $4(20)$ & $27(36)$ & 0.1751 \\
Sport $* *$ & $2(10)$ & $23(30.67)$ & 0.062 \\
Dominant hand, right*** & $19(95)$ & $69(92)$ & $>0.999$ \\
\hline
\end{tabular}

*mean \pm standard deviation; Student t-test for independent samples, ** no (\%), Chi-square test; *** no (\%), Fisher exact test 
Forty-six joints and 24 tendon units were evaluated clinically and MSUS in each subject, totalizing 920 joint $/ 480$ tendon sites in the case group and 3450 joint $/ 1800$ tendon sites in the control group.

\section{Clinical evaluation}

On $1^{\text {st }}$ visit, in both case group and control group, CE did not identify any pathologic findings.

On $2^{\text {nd }}$ visit, one pregnant woman became symptomatic (5\% of the case group; painful knees) and on the $3^{\text {rd }}$ visit, 11 pregnant subjects (55\%) developed symptoms and inflammation signs in large joints and lower limb tendons. Postpartum, the number of symptomatic joints dropped progressively (fig 1). The symptomatic women presented transitory large joint inflammatory symptoms and signs at $\mathrm{CE}$ during the $2^{\text {nd }}, 3^{\text {rd }}$ pregnancy trimester, in some cases extended in the postpartum period on $4^{\text {th }}$ visit.

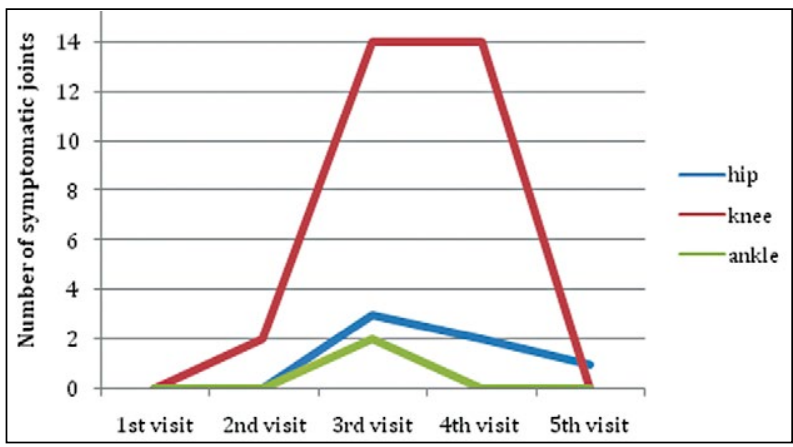

Fig 1. Longitudinal analysis of the number of symptomatic joints in the case group
One woman presented persistent hip pain from the $3^{\text {rd }}$ up to the $5^{\text {th }}$ visit. One woman presented symptomatic transitory TPT involvement with the onset in the $3^{\text {rd }}$ trimester lasting on $4^{\text {th }}$ visit and with remission on $5^{\text {th }}$ visit .

\section{US findings at groups level}

The case group presented at least one pathologic imaging finding on minimum one visit: $14(70 \%$, $95 \% \mathrm{CI}$ [45.25-89.75]) on the $1^{\text {st }}$ visit, $15(75 \%, 95 \% \mathrm{CI}$ [50.25-89.75]) on the $2^{\text {nd }}$ visit and $19(95 \%, 95 \% \mathrm{CI}$ [75.25-99.75]) on the $3^{\text {rd }}$ visit.

In the control group, 71 subjects $(94.66 \%, 95 \% \mathrm{CI}$ [86.68-98.65]) presented at least one pathologic-like imaging finding.

\section{US findings at joint and tendon level}

The frequency and distribution of joint and tendon inflammatory-like GS abnormalities, in both groups, is presented in Table II.

The highest frequency of inflammatory-like lesions was detected in both groups at the level of the MTPj but the control group was significantly more frequently affected, when compared to the case group, comparisons were made for the first four visits $\left(\mathrm{p}_{1 \text { st visit }}=0.001, \mathrm{p}_{2 \text { nd visit }}\right.$ $\left.=0.001, \mathrm{p}_{3 \text { rd visit }}=0.009, \mathrm{p}_{\text {4th visit }}=0.014\right)$. Results on MTPj5 showed 10 joints with $\mathrm{SH} / \mathrm{E}$ grade 1 and no PD in the control group. No SH/E/PD signal was found in MTPj5 in the case group, at any point of evaluation. A similar pattern to the global MTPj evaluation was observed in the wrist joints. A higher frequency of inflammatorylike imaging findings was identified in the control group as compared to the case group in the first four visits

Table II. Summary and distribution of inflammatory joint and tendon pathology (grey scale) by groups.

\begin{tabular}{|c|c|c|c|c|c|c|}
\hline \multirow[t]{2}{*}{$\begin{array}{l}\text { Joint } \\
\end{array}$} & \multirow[t]{2}{*}{ Control group no (\%) } & \multicolumn{5}{|c|}{ Case group no (\%) } \\
\hline & & $1^{\text {st }}$ visit & $2^{\text {nd }}$ & $3^{\text {rd }}$ & $4^{\text {th }}$ & $5^{\text {th }}$ \\
\hline Wrist ${ }^{a}$ & $57(38)$ & $8(20)$ & $8(20)$ & $8(20)$ & $8(20)$ & $11(27.5)$ \\
\hline MCP $1^{\text {a }}$ & $4(2.67)$ & 0 & 0 & 0 & 0 & 0 \\
\hline MCP $2-5^{b}$ & $21(3.5)$ & 0 & 0 & 0 & 0 & 0 \\
\hline PIP $1-5 \mathrm{c}$ & $17(2.26)$ & 0 & 0 & 0 & 0 & 0 \\
\hline MTP $1-5$ a & $333(44.4)$ & $66(33)$ & $66(33)$ & $71(35.5)$ & $72(36)$ & $76(38)$ \\
\hline ELBOW a & 0 & 0 & 0 & 0 & 0 & 0 \\
\hline $\mathrm{KNEE}^{\mathrm{a}}$ & $16(10.67)$ & 0 & $10(25)$ & $37(92.5)$ & $38(95)$ & 0 \\
\hline TTJ a & 0 & 0 & 0 & $5(12.5)$ & $4(10)$ & 0 \\
\hline TNJ a & 0 & 0 & 0 & 0 & 0 & 0 \\
\hline $\mathrm{STJ}^{\mathrm{a}}$ & $2(1.33)$ & 0 & 0 & 0 & 0 & 0 \\
\hline HIP a & 0 & 0 & 0 & $3(7.5)$ & $3(7.5)$ & $1(2.5)$ \\
\hline $\mathrm{GH}^{\mathrm{a}}$ & 0 & 0 & 0 & 0 & 0 & 0 \\
\hline \multicolumn{7}{|l|}{ Tendons } \\
\hline $\mathrm{C} 1-\mathrm{C} 5^{\mathrm{c}}$ & $1(0.13)$ & $1(0.5)$ & $1(0.5)$ & $15(7.5)$ & $15(7.5)$ & $1(0.5)$ \\
\hline $\mathrm{F} 1-\mathrm{F} 5^{\mathrm{c}}$ & $1(0.13)$ & 0 & 0 & 0 & 0 & 0 \\
\hline $\mathrm{TPT}^{\mathrm{a}}$ & $1(0.67)$ & 0 & 0 & $30(75)$ & $30(75)$ & 0 \\
\hline EUC $^{\text {a }}$ & $1(0.67)$ & $1(2.5)$ & $1(2.5)$ & $1(2.5)$ & $1(2.5)$ & $1(2.50)$ \\
\hline
\end{tabular}

$\mathrm{MCP}$ - metacarpophalangeal joint, PIP - proximal interfalangeal joint, MTP - metatarsophalangeal joint, $\mathrm{TTj}$ - tibiotalar joint, $\mathrm{TNj}$ - talonavicular joint, $\mathrm{STj}$ - subtalar joint, $\mathrm{C} 1-\mathrm{C} 5$ - wrist extensor compartments 1-5, F1-F5 - flexor tendons of the digits $1-5$, TPT - tibialis posterior tendon, EUC - extensor carpi ulnaris tendon; ${ }^{a} n=150$ for control group and $n-40$ for case group; ${ }^{b} n=600$ for control group and $n=160$ for case group; ${ }^{c} n=750$ for control group and $n=200$ for case group. 
$(\mathrm{p}=0.041)$. In contrast to these findings, the knee joints were significantly more affected in pregnant women on $3^{\text {rd }}$ and $4^{\text {th }}$ visit evaluation, mainly due to the presence of effusion $(p<0.0001)$. Furthermore, 3 cases of hip joint capsular distension were observed among pregnant women starting with the $3^{\text {rd }}$ visit. Postpartum X-ray and MRI evaluation identified 2 hips with transitory osteoporosis in pregnancy and one with aseptic osteonecrosis.

The frequency of GS tendon pathology was very low in the control group (just one tendon with abnormalities in each category of F1-F5, C1-C6 and TPT). The same results were identified for pregnant subjects in the $1^{\text {st }}$ trimester of pregnancy. TPT and extensor compartments C1-C5 (mainly C4) were significantly more affected $(\mathrm{p}<0.0001)$ on the $3^{\text {rd }}$ and $4^{\text {th }}$ visit in comparison to the $1^{\text {st }}$ and $5^{\text {th }}$ visit. In contrast, no flexor tendon (F1-F5) pathology was detected in the case group, at any point vs one flexor tendon pathology in the control group (F1). No MCPj 1-5 imaging abnormalities were detected in the case group at any point. In the control group, 3.5\% of the MCPj 2-5 presented GS abnormalities, but when quantification was made only for inflammatory lesions more than grade 1 , this result dropped to $1 \%$. No control presented PD signal at joint/tendon level. In the case group, very few PD signals (mainly grade 1) were identified only in the MTP $\mathrm{j}-1$ joint on $1^{\text {st }}$ visit, 2 joints on $2^{\text {nd }}$ visit, 7 joints on $3^{\text {rd }}$ visit and 1 joint on $5^{\text {th }}$ visit. Intratendon sheath positive PD signal was identified only in 2
TPT (tendons with GS signs of tenosynovitis) on $3^{\text {rd }}$ visit vs zero PD in the rest of the visits. In the case group, no erosion was detected. In the control group one erosion was detected at the level of MTPj 1 . In both groups a low frequency of osteophytes was identified, almost exclusively located at the level of the PIPj.

\section{US findings at anatomical structure level}

Table III presents distribution of abnormal findings on GS and PD in joints and tendons, stratified by groups. The evolution of the MSUS findings is presented in figure 2 and 3 .

Effusion significantly increased from the $1^{\text {st }}$ till the $4^{\text {th }}$ visit $(\mathrm{p}<0.0001)$ and dropped down on the $5^{\text {th }}$ visit to the value close to the $1^{\text {st }}$ visit, for both joints and tendons. The same pattern was observed for effusion higher than grade $1, p<0.0001$. Furthermore, for joint effusion higher than grade 1, statistically significant increase was also depicted, when the $1^{\text {st }}$ visit was compared to the $2^{\text {nd }}$ visit $(\mathrm{p}<0.0001)$.

All symptomatic joints detected at $\mathrm{CE}$, but not asymptomatic large joints ( $\mathrm{GHj}$, elbow, hip, TTj), presented MSUS detectable inflammatory abnormalities. Many knee joints with effusion, TPT and extensor compartments with tendon sheath effusion remained asymptomatic. GS tendon pathology was represented mostly by effusion. We detected only 2 TPT with SH and PD in one pregnant patient on the $3^{\text {rd }}$ visit. All the other affected tendons presented only effusion.

Table III. Summary of US findings on joints and tendons by group and visit, expressed as percent and associated $95 \%$ confidence intervals (provided in squared brackets)

\begin{tabular}{|c|c|c|c|c|c|c|}
\hline \multirow[t]{2}{*}{ US finding } & \multicolumn{5}{|l|}{ Case } & \multirow[t]{2}{*}{ Control } \\
\hline & $1^{\text {st }}$ Visit & $2^{\text {nd }}$ Visit & $3^{\text {rd }}$ Visit & $4^{\text {th }}$ Visit & $5^{\text {th }}$ Visit & \\
\hline \multicolumn{7}{|l|}{ Joints } \\
\hline $\mathrm{SH}$ & $\begin{array}{l}9.35^{\mathrm{a}} \\
{[7.63-11.40]}\end{array}$ & $\begin{array}{l}9.35^{\mathrm{a}} \\
{[7.63-11.40]}\end{array}$ & $\begin{array}{l}10.33^{\mathrm{a}} \\
{[8.53-12.46]}\end{array}$ & $\begin{array}{l}10.43^{\mathrm{b}} \\
{[8.62-12.57]}\end{array}$ & $\begin{array}{l}10.98 \\
{[9.12-13.16]}\end{array}$ & $\begin{array}{l}8.37 \\
{[7.64-9.16]}\end{array}$ \\
\hline $\mathrm{SH}>$ grade 1 & $\begin{array}{l}0.76^{\mathrm{c}} \\
{[0.37-1.56]}\end{array}$ & $\begin{array}{l}0.87^{\mathrm{c}} \\
{[0.44-1.71]}\end{array}$ & $\begin{array}{l}1.20^{\mathrm{c}} \\
{[0.67-2.13]}\end{array}$ & $\begin{array}{l}1.09^{c} \\
{[0.59-1.99]}\end{array}$ & $\begin{array}{l}0.87^{\mathrm{c}} \\
{[0.44-1.71]}\end{array}$ & $\begin{array}{l}3.16 \\
{[2.71-3.68]}\end{array}$ \\
\hline $\mathrm{E}$ & $\begin{array}{l}13.28^{\mathrm{a}} \\
{[10.87-16.13]}\end{array}$ & $\begin{array}{l}14.84 \\
{[12.30-17.80]}\end{array}$ & $\begin{array}{l}20.31 \\
{[17.37-23.60]}\end{array}$ & $\begin{array}{l}20.31 \\
{[17.37-23.60]}\end{array}$ & $\begin{array}{l}14.53^{\mathrm{a}} \\
{[12.01-17.47]}\end{array}$ & $\begin{array}{l}17.88 \\
{[16.40-19.46]}\end{array}$ \\
\hline $\mathrm{E}>$ grade 1 & $\begin{array}{l}2.66^{\mathrm{d}} \\
{[1.67-4.22]}\end{array}$ & $\begin{array}{l}5.47 \\
{[3.96-7.51]}\end{array}$ & $\begin{array}{l}12.50^{\mathrm{d}} \\
{[10.16-15.29]}\end{array}$ & $\begin{array}{l}10.94^{\mathrm{d}} \\
{[8.75-13.60]}\end{array}$ & $\begin{array}{l}3.75 \\
{[2.53-5.55]}\end{array}$ & $\begin{array}{l}4.67 \\
{[3.90-5.59]}\end{array}$ \\
\hline Power Doppler & $\begin{array}{l}0 \\
{[0.00-0.42]}\end{array}$ & $\begin{array}{l}0.11 \\
{[0.02-0.62]}\end{array}$ & $\begin{array}{l}0.76 \\
{[0.33-1.52]}\end{array}$ & {$[0.02-0.62]$} & $\begin{array}{l}0.11 \\
{[0.02-0.62]}\end{array}$ & $\begin{array}{l}0.06 \\
{[0.02-0.17]}\end{array}$ \\
\hline Osteophytes & $\begin{array}{l}6.25 \\
{[4.62-8.40]}\end{array}$ & $\begin{array}{l}6.25 \\
{[4.62-8.40]}\end{array}$ & $\begin{array}{l}6.25 \\
{[4.62-8.40]}\end{array}$ & $\begin{array}{l}6.25 \\
{[4.62-8.40]}\end{array}$ & $\begin{array}{l}6.25 \\
{[4.62-8.40]}\end{array}$ & $\begin{array}{l}7.13 \\
{[6.16-8.22]}\end{array}$ \\
\hline \multicolumn{7}{|l|}{ Tendons } \\
\hline $\mathrm{SH}+\mathrm{E}$ & $\begin{array}{l}0.42 \\
{[0.12-1.51]}\end{array}$ & $\begin{array}{l}0.42 \\
{[0.12-1.51]}\end{array}$ & $\begin{array}{l}9.58 \\
{[7.26-12.66]}\end{array}$ & $\begin{array}{l}9.58 \\
{[7.26-12.66]}\end{array}$ & $\begin{array}{l}0.42 \\
{[0.12-1.51]}\end{array}$ & $\begin{array}{l}0.22 \\
{[0.09-0.57]}\end{array}$ \\
\hline $\mathrm{SH}+\mathrm{E}>$ grade 1 & $\begin{array}{l}0.00 \\
{[0.00-0.79]}\end{array}$ & $\begin{array}{l}0.00 \\
{[0.00-0.79]}\end{array}$ & $\begin{array}{l}2.92 \\
{[1.75-4.84]}\end{array}$ & $\begin{array}{l}2.92 \\
{[1.75-4.84]}\end{array}$ & $\begin{array}{l}0.00 \\
{[0.00-0.79]}\end{array}$ & $\begin{array}{l}0.00 \\
{[0.00-0.21]}\end{array}$ \\
\hline Power Doppler & $\begin{array}{l}0.00 \\
{[0.00-0.79]}\end{array}$ & $\begin{array}{l}0.00 \\
{[0.00-0.79]}\end{array}$ & $\begin{array}{l}0.42 \\
{[0.00-1.67]}\end{array}$ & $\begin{array}{l}0.00 \\
{[0.00-0.79]}\end{array}$ & $\begin{array}{l}0.00 \\
{[0.00-0.79]}\end{array}$ & $\begin{array}{l}0.00 \\
{[0.00-0.21]}\end{array}$ \\
\hline
\end{tabular}

$\mathrm{SH}$ - synovial hypertrophy, GS - grey scale, $\mathrm{E}$ - effusion. a $\mathrm{p}<0.05$ as compared to the control group; $\mathrm{b} p=0.0516$ as compared to control group; $\mathrm{c} p<0.005$ as compared to the control group; $\mathrm{d} p<0.03$ as compared to the control group 


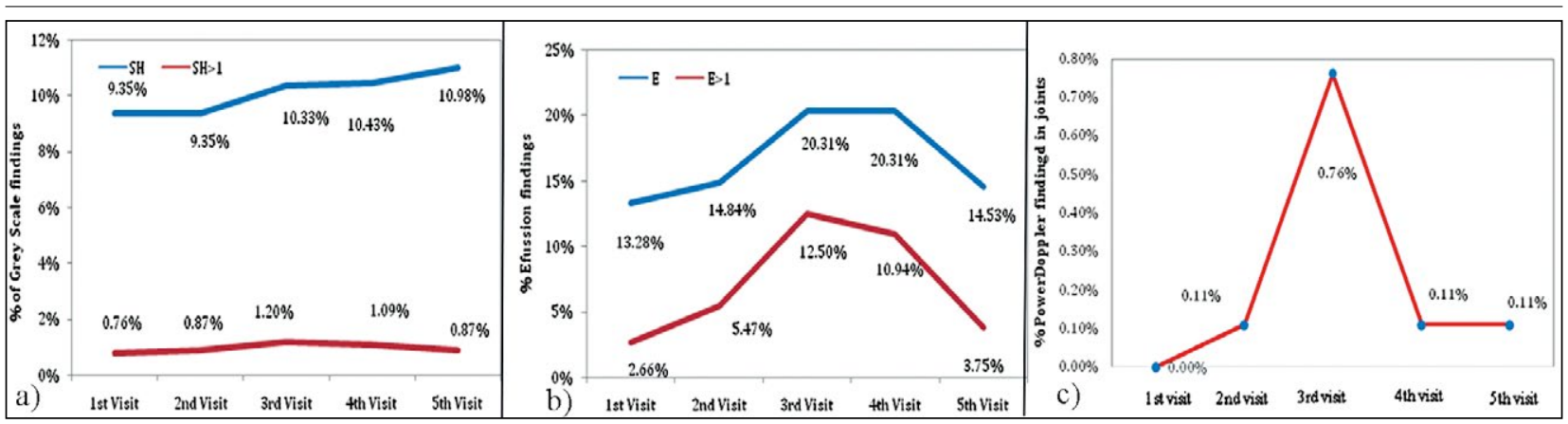

Fig 2. Evolution throughout pregnancy and postpartum of: a) synovial hypertrophy (grey scale) in joints; b) effusion in joints; c) power Doppler findings in joints PD- power Doppler signal. E-effusion. SH- synovial hypertrophy

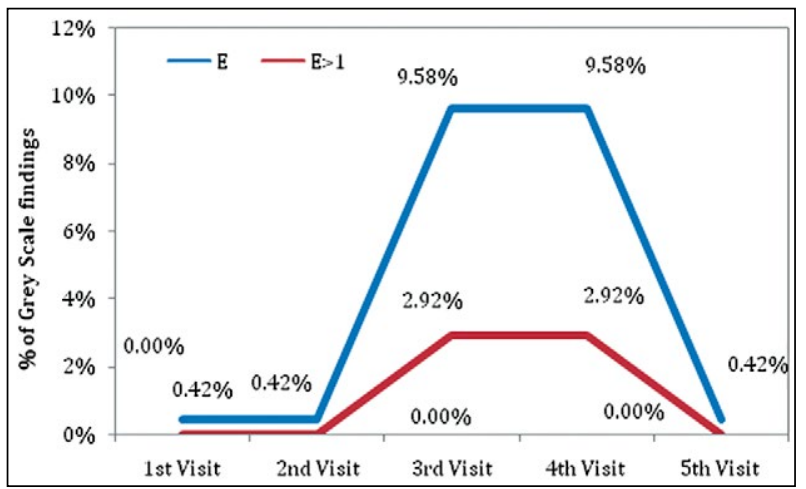

Fig 3. Evolution of grey scale findings (effusion) overall and more than grade 1 , in tendons, throughout pregnancy and postpartum. E-effusion.

No subject in the case group was found to develop any kind of rheumatic inflammatory disease during the follow-up interval.

\section{Discussions}

Our study presents for the first time a prospective controlled longitudinal data analysis on MSUS evaluation in healthy pregnant subjects. The importance derives from the fact that the case group was exposed to a temporary modified immune tolerance, hormonal stimulation (higher concentrations of estrogens, progesterone and cortisol), higher central and peripheral blood perfusion and rapid weight gain, creating a physiological model of progressive multi-factorial impact. Progressive disappearance of these factors in the postpartum period creates the possibility to identify the reversible MSUS joint and tendon pregnancy-induced abnormalities. Therefore, the normality spectrum in healthy subjects would be better understood.

Published data regarding MSUS evaluation in healthy subjects, has highlighted some important facts until now.
GS inflammatory pathology-like findings (mostly mild and consisting more in effusion) have higher prevalence in MTPj, moderate in wrists (mostly on the dominant hand) and a lower prevalence at MCPj, PIPj and large joints level, at one point in time. These modifications correlate usually with biomechanical factors and age $[23,26]$. The meaning of tenosynovitis/tenosynovitis-like modifications and PD signal (on joint and tendon level) still has to be better defined in healthy groups. Only scarce and contradictory information regarding tendon involvement was published until now [29].

In our study, the highest percentage of joint involvement, mostly of a mild degree, was identified in both groups, in the MTPj and in the wrists, especially in the dominant hand, probably being linked to biomechanical and vascular factors. For the case group, a higher incidence was observed in the last trimester of pregnancy and in the first postpartum period. A very low number of joints, exclusively MTPj, displayed temporary low-grade PD signal (0.5-3\%), with a peak within the $3^{\text {rd }}$ trimester $v s$ no PD signal in the control group on any level. This result is supported by a series of other studies, with healthy nonpregnant subjects, where a variable percentage of mild MTPj and wrists GS pathology was identified (68.4\%93.7\% MTPj and 50\% of the wrists) $[19,20,23,26]$.

According to the described results, we add here our opinion and confirm that MTPj inflammatory-like abnormalities are frequent in healthy subjects and should be excluded from the global joint count for early diagnose purpose and disease activity measurements, as previously stated by Padovano et al [26].

The most striking result in our work was the absence of any flexor tendon (F1-F5) and MCPj 2-5 pathologiclike lesions (GS and PD) in the case group. Pregnancy did not alter these findings, when longitudinal evaluation was made. A low prevalence of MCPj pathology ( $\mathrm{SH}, \mathrm{E})$ of grade 1 and 2 was identified in the control group in older subjects and dropped dramatically when MCPj with a GS/ 
PD abnormalities grade $>1$ were selected. Only one subject in each group presented a unilateral EUC tenosynovitis and this was a constant finding during the pregnancy and postpartum. In our opinion, these results select F1-F5, $\mathrm{MCPj}$ and EUC tendon as sites with very low frequency and unilateral distribution of pathology-like changes in healthy non-pregnant and pregnant subjects. Out of all evaluated sites and in line with the RA classification criteria [38], this joint and tendon set shows to be most suitable for early disease detection or disease monitoring purposes.

MRI studies of tendons in healthy subjects showed discordant findings - low prevalence of pathologic findings $[24,39,40]$ or high prevalence of tendon sheath effusion in the digit flexor and ankle tendons $[29,41]$.

Similar to our study, a pattern of low profile MCPj synovitis and erosions in healthy subjects was highlighted by previous studies. Ejbjerg et al identified low-grade synovitis-like changes in $8.9 \% \mathrm{MCPj}$ and in $9.5 \%$ wrists of dominant hand using MRI. Only minimal early synovial enhancement was detected by dynamic MRI in these areas. Low-grade erosion-like changes were found in $2.2 \% \mathrm{MCPj}$ and in $1.7 \%$ wrists, but post-contrast enhancement within the lesion was detected in only $8.3 \%$ of these cases [42]. The same conclusions are supported by Rowbotham et al which found synovitis in only $8.8 \%$ of evaluated MCPj [39].

Ellegaard et al [19] highlighted the fact that pathology definitions and scoring systems, suitable for RA patients, when applied to healthy subjects artificially generate an unacceptable high number of joints labeled as pathologic. In the authors' opinion, these results would depend on various factors such as: normal anatomy and variation in synovial thickness, lack of definitions for echogenicity of hypertrophic synovial tissue and hypoechogenicity, and ultrasound equipment setting.

Fodor et al found on 50 healthy volunteers a very low prevalence of inflammatory MCPj pathologic findings. Furthermore, the authors analyzed the problem of possible confounders: the truncate apex of the dorsal plate which may give the false impression of synovitis and the presence of PD signal in joints without GS synovitis which should be considered normal [25]. The same conclusion was previously issued by Terslev et al in a study on healthy subjects where Doppler activity was detected most commonly in the wrist, carpometacarpal joint $1, \mathrm{MCPj}$ and PIPj [43]. In contrast to these findings, Zufferey et al found grade 1 PD signal in about $5 \%$ of normal volunteers (distribution not specified) and considered this as a relevant pathologic finding, when RA patients in remission are evaluated [44].

A recent MSUS study evaluated healthy subjects at joint sites comprising the DAS28 joint set, ankles and MTPj; a very low prevalence of MCPj pathology was found. The GS SH score correlated with increasing age but not with the measured cytokines. PD signal in normal joints was rarely observed and was correlated with vascular endothelial growth factor. The authors concluded that PD could be used as an inflammation parameter for assessment, especially in the elderly population [23].

Padovano et al showed a relatively low prevalence of MSUS abnormalities on joint level (9\%). Effusion was the most frequently detected MSUS abnormality in terms of subjects and joints (52\% vs 69\%) and mild $\mathrm{SH}$ was found mostly in MTPj. SH associated with positive PD signal was rare, suggesting that PD abnormalities are more likely to be specific for synovial inflammation [26].

At this point, our results support previously published data, hypothesizing that hand flexor tendons, MCPj and EUC tendons are important target structures to be evaluated when early stage of RA is suspicioned [39]. The presence of PD is more likely to be specific for inflammation, especially when present on bilateral hand joint level. In contrast to this, it seems that in healthy subjects, the prevalence of imaging pathology in these structures is very low or even absent, showing unilateral hand involvement. The same trend was kept when longitudinal evaluation was made.

The most important longitudinal changes for inflammatory-like pathology in the case group were present in the knee joints, $\mathrm{C} 4$ extensor compartment of the dominant hand and TPTs. These longitudinal changes were identified as being present only in the interval of the $2^{\text {nd }}$ and $3^{\text {rd }}$ trimester and $4^{\text {th }}$ postpartum visit and showed statistical significance only for the effusion component. We concluded that effusion quantification with MSUS should be eliminated, when monitoring patients with chronic inflammatory diseases. We are partially in agreement here with the conclusions of Padovano et al, the authors expressing the recommendation for effusion exclusion from disease diagnosis and monitoring [26]. In contrast, we still believe that effusion may have a certain importance and contribution in an accurate MSUS quantification at disease onset. In our study, effusion was the component that was detected in those joints, that became symptomatic in the case group, raising the problem of a true inflammatory finding, but this phenomenon was present (with one exception) only in large joints.

Our study has the advantage of presenting for the first time longitudinal controlled data on MSUS abnormalities in pregnant patients. The analysis gave us the possibility to depict joints and tendons that "react" to pregnancy and those that "don't react" to it. Indeed, we were able to define the joint and tendon set less exposed to pathologylike abnormalities, less exposed to physiological variations among individuals and in time. A better characteri- 
zation of the spectrum of normality allowed us to identify more suitable targets for disease onset identification.

The drawback in our study was the small number of pregnant subjects, the selection in real life proved to be extremely difficult for those attending all 5 visits. Some bias could have been produced by the fact that symptomatic pregnant subjects showed more discipline in coming to the scheduled visits because they were more concerned about their health status. Also, the MSUS evaluation was made only by one MSUS expert with an experience of over 10 years. Previous reliability exercises involving our MSUS expert showed a good and very good overall agreement and inter-observer agreement for all MSUS evaluated $[25,45,46]$. No comparison with another imaging methods was made because of safety reasons in pregnant population.

In conclusion, our study confirms that mild US abnormalities suggesting inflammation (ie, $\mathrm{SH}, \mathrm{E}$ and intrasynovial PD) can be detected with low frequency in healthy subjects and that exposure to a cumulus of hormonal, vascular and biomechanical factors may modify baseline findings. Therefore, effusion in joints and tendon sheaths, mostly of grade 1 and 2 , showed a significant longitudinal increase during pregnancy, proving that this kind of abnormality may belong mostly to the normality spectrum. In addition, the fact that some of the joints and tendons became symptomatic, pleads for the hypothesis that, at least some of the newly added MSUS abnormalities represented true inflammatory modifications.

The identification of a joint/tendon set with less abnormalities (hand flexor tendons F1-F5, MCPj 2-5 and EUC) in healthy subjects would help in selecting target structures, important for identifying disease onset and for further disease monitoring. Further prospective longitudinal studies on larger cohorts are needed, because the very thin border between physiological and borderline pathological findings still has to be better defined.

\section{References}

1. Lawry GV. Systematic musculoskeletal examinations. McGraw-Hill Medical, 2011.

2. Möller I, Janta I, Backhaus M, et al. The 2017 EULAR standardised procedures for ultrasound imaging in rheumatology. Ann Rheum Dis 2017;76:1974-1979.

3. Backhaus M, Kamradt T, Sandrock D, et al. Arthritis of the finger joints: a comprehensive approach comparing conventional radiography, scintigraphy, ultrasound, and contrast-enhanced magnetic resonance imaging. Arthritis Rheum 1999;42:1232-1245.

4. Backhaus M, Burmester GR, Sandrock D, et al. Prospective two year follow up study comparing novel and conven- tional imaging procedures in patients with ar- thritic finger joints. Ann Rheum Dis 2002;61:895-904.

5. Grassi W, Salaffi F, Filippucci E. Ultrasound in rheumatology. Best Pract Res Clin Rheumatol 2005;19:467-485.

6. Kane D, Balint PV, Sturrock RD. Ultrasonography is superior to clinical examination in the detection and localization of knee joint effusion in rheumatoid arthritis. J Rheumatol 2003;30:966-971.

7. Karim Z, Wakefield RJ, Quinn M, et al. Validation of ultrasonography in the detection of synovitis in the knee: a comparison with arthroscopy and clinical examination. Arthritis Rheum 2004;50:387-394.

8. Szkudlarek M, Narvestad E, Klarlund M, Court-Payen M, Thomsen HS, Ostergaard M. Ultrasonography of the metatarsophalangeal joints in rheumatoid arthritis: comparison with magnetic resonance imaging, conventional radiography, and clinical examination. Arthritis Rheum 2004;50:2103-2112.

9. Taylor PC, Steuer A, Gruber J, et al. Comparison of ultrasonographic assessment of synovitis and joint vascularity with radiographic evaluation in a randomized, placebocontrolled study of infliximab therapy in early rheumatoid arthritis. Arthritis Rheum 2004;50:1107-1116.

10. Wakefield RJ, Green MJ, Marzo-Ortega H, et al. Should oligoarthritis be reclassified? Ultrasound reveals a high prevalence of subclinical disease. Ann Rheum Dis 2004;63:382-385.

11. Hau M, Kneitz C, Tony HP, Keberle M, Jahns R, Jenett M. High resolution ultrasound detects a decrease in pannus vascularisation of small finger joints in patients with rheumatoid arthritis receiving treatment with soluble tumour necrosis factor alpha receptor (etanercept). Ann Rheum Dis 2002;61:55-58.

12. Iagnocco A, Finucci A, Ceccarelli F, Perricone C, IorgoveanuV, Valesini G. Power Doppler ultrasound monitoring of response to anti-tumor necrosis factor alpha treatment in patients with rheumatoid arthritis. Rheumatology (Oxford) 2015;54:1890-1896.

13. Filippucci E, Iagnocco A, Salaffi F, Cerioni A, Valesini G, Grassi W. Power Doppler sonography monitoring of synovial perfusion at the wrist joints in patients with rheumatoid arthritis treated with adalimumab. Ann Rheum Dis 2006;65:1433-1437.

14. Naredo E, Crespo M, Campos C, et al. Validity, reproducibility, and responsiveness of a twelve-joint simplified power doppler ultrasonographic assessment of joint inflammation in rheumatoid arthritis. Arthritis Rheum 2008;4:515-522.

15. Ribbens C, André B, Marcelis S, et al. rheumatoid hand joint synovitis: gray-scale and power doppler us quantifications following anti-tumor necrosis factor-alpha treatment: pilot study. Radiology 2003;229:562-569.

16. Hammer HB, Kvien TK. Ultrasonography shows significant improvement in wrist and ankle tenosynovitis in rheumatoid arthritis patients treated with adalimumab. Scand J Rheumatol 2011;40:178-182.

17. Døhn UM, Ejbjerg B, Boonen A, et al. No overall progression and occasional repair of erosions despite persistent inflammation in adalimumab-treated rheumatoid arthritis 
patients: results from a longitudinal comparative MRI, ultrasonography, CT and radiography study. Ann Rheum Dis 2011;70:252-258.

18. Hartung W, Kellner H, Strunk J, et al. Development and evaluation of a novel ultrasound score for large joints in rheumatoid arthritis: one year of experience in daily clinical practice. Arthritis Care Res 2012;64:675-682.

19. Ellegaard K, Torp-Pedersen S, Holm CC, DanneskioldSamsøe B, Bliddal H. Ultrasound in finger joints: findings in normal subjects and pitfalls in the diagnosis of synovial disease. Ultraschall Med 2007;28:401-408.

20. Millot F, Clavel G, Etchepare F, et al; Investigators of the French Early Arthritis Cohort ESPOIR. Musculoskeletal ultrasonography in healthy subjects and ultrasound criteria for early arthritis (the ESPOIR cohort). J Rheumatol 2011;38:613-620.

21. Szkudlarek M, Klarlund M, Narvestad E, et al. Ultrasonography of the metacarpophalangeal and proximal interphalangeal joints in rheumatoid arthritis: a comparison with magnetic resonance imaging, conventional radiography and clinical examination. Arthritis Res Ther 2006;8:R52.

22. Witt M, Mueller F, Nigg A, et al. Relevance of grade 1 grayscale ultrasound findings in wrists and small joints to the assessment of subclinical synovitis in rheumatoid arthritis. Arthritis Rheum 2013;65:1694-1701.

23. Kitchen J, Kane D. Greyscale and power Doppler ultrasonographic evaluation of normal synovial joints: correlation with pro- and anti-inflammatory cytokines and angiogenic factors. Rheumatology (Oxford) 2015;54:458-462.

24. Parodi M, Silvestri E, Garlaschi G, Cimmino MA. How normal are the hands of normal controls? A study with dedicated magnetic resonance imaging. Clin Exp Rheumatol 2006;24:134-141.

25. Fodor D, Felea I, Popescu D, et al. Ultrasonography of the metacarpophalangeal joints in healthy subjects using an 18 MHz transducer. Med Ultrason 2015;17:185-191.

26. Padovano I, Costantino F, Breban M, D'Agostino MA. Prevalence of ultrasound synovial inflammatory findings in healthy subjects. Ann Rheum Dis 2016;75:1819-1823.

27. Grassi W, Tittarelli E, Blasetti P, Pirani O, Cervini C. Finger tendon involvement in rheumatoid arthritis. Evaluation with high frequency sonography. Arthritis Rheum 1995;38:786-794.

28. Grassi W, Filippucci E, Farina A, Cervini C. Sonographic imaging of tendons. Arthritis Rheum 2000;43:969-976.

29. Agten CA, Rosskopf AB, Jonczy M, Brunner F, Pfirrman CWA, Buck FM. Frequency of inflammatory-like MR imaging findings in asymptomatic fingers of healthy volunteers. Skeletal Radiol 2018;47:279-287.

30. Ostensen M, Fuhrer L, Mathieu R, Seitz M, Villiger PM. A prospective study of pregnant patients with rheumatoid arthritis and ankylosing spondylitis using validated clinical instruments. Ann Rheum Dis 2004;63:1212-1217.

31. de Man YA, Hazes JM, van de Geijn FE, Krommenhoek C, Dolhain RJ.

32. Measuring disease activity and functionality during pregnancy in patients with rheumatoid arthritis. Arthritis Rheum 2007;57:716-722.
33. Ostensen M. Sexual and reproductive health in rheumatic disease. Nat Rev Rheumatol 2017;13:485-493.

34. Wakefield RJ, Balint PV, Szudlarek M, et al. Musculoskeletal ultrasound including definitions for ultrasonographic pathology. J Rheumatol 2005;32:2485-2487.

35. Szkudlarek M, Court-Payen M, Jacobsen S, Klarlund M, Thomsen HS, Ostergaard M. Interobserver agreement in ultrasonography of the finger and toe joints in rheumatoid arthritis. Arthritis Rheum 2003;48:955-962.

36. Naredo E, d'Agostino MA, Wakefield RJ, et al; OMERACT Ultrasound Task Force. Reliability of a consensus-based ultrasound score for tenosynovitis in rheumatoid arthritis. Ann Rheum Dis 2013;72:1328-1334.

37. Jäntschi L, Bolboacă SD. Exact probabilities and confidence limits for binomial samples: applied to the difference between two proportions. ScientificWorldJournal 2010;10:865-878.

38. Aletaha D, Neogi T, Silman AJ, et al. 2010 Rheumatoid arthritis classification criteria: an American College of Rheumatology/European League Against Rheumatism collaborative initiative. Ann Rheum Dis 2010;69:1580-1588.

39. Rowbotham EL, Freeston JE, Emery P, Grainger AJ. The prevalence of tenosynovitis of the interosseous tendons of the hand inpatients with rheumatoid arthritis. Eur Radiol 2016;26:444-450.

40. Navalho M, Resende C, Rodrigues AM, et al. Bilateral MR imaging of the hand and wrist in early and very early inflammatory arthritis: tenosynovitis is associated with progression to rheumatoid arthritis. Radiology 2012;264:823833.

41. Schweitzer ME, van Leersum M, Ehrlich SS, Wapner K. Fluid in normal and abnormal ankle joints: Amount and distribution as seen on MRI images. AJR Am J Roentgenol 1994;162:111-114.

42. Ejbjerg B, Narvestad E, Rostrup E, et al. Magnetic resonance imaging of wrist and finger joints in healthy subjects occasionally shows changes resembling erosions and synovitis as seen in rheumatoid arthritis. Arthritis Rheum 2004;50:1097-1106.

43. Terslev L, Torp-Pedersen S, Qvistgaard E, von der Recke $\mathrm{P}$, Bliddal H. Doppler ultrasound findings in healthy wrists and finger joints. Ann Rheum Dis 2004;63:644-648.

44. Zufferey P, Möller B, Brulhart L, et al. Persistence of ultrasound synovitis in patients with rheumatoid arthritis fulfilling the DAS28 and/or the new ACR/ EULAR RA remission definitions: results of an observational cohort study. Joint Bone Spine 2014;81:426-432.

45. Vlad V, Berghea F, Iagnocco A, et al. Inter \& intra-observer reliability of grading ultrasound videoclips with hand pathology in rheumatoid arthritis by using non- sophisticated internet tools (LUMINA study). Med Ultrason 2014;16:3236.

46. Micu MC, Serra S, Fodor D, Crespo M, Naredo E. Interobserver reliability of ultrasound detection of tendon abnormalities at the wrist and ankle in patients with rheumatoid arthritis. Rheumatology (Oxford) 2011;50:1120-1124. 